\title{
Patients' Satisfaction with Primary Health Care in Egypt: Exploring the Gap between Rural and Urban Governorates
}

\author{
Dina Metwally \\ Helwan University, Egypt \\ dinametwally2001@googlemail.com
}

\begin{abstract}
Patient satisfaction has been frequently used as an indication of the overall quality of health care providers. Understanding patients ' needs and expectations is crucial to PHC providers to improve patients' health. This study aims to explore patients' satisfaction with primary health care services in urban and rural areas in Egypt. The study shows a gap in patient's satisfaction across Alexandria and Sohag governorates. This implies a difference in reform implementation across urban and rural governorates. More attention should be given to different dimensions of health care provision at PHC level in rural governorates including clinical and nonclinical training of nurses, improvement in amenities and other facilities, improvement of registration system, and promoting the new system.
\end{abstract}

Keywords: Primary health care (PHC), GPS, patients' satisfaction

\section{Introduction}

Consumer satisfaction has been an important factor in measuring the performance of different types of organizations. It is concerned with the extent to which consumers feel that their needs and expectations are met by service provider (Al-Doghaither \& Saeed, 2000, p. 448). Such concern with consumerism highlights the central role of patients in the planning and delivery of health care services (Baker et al., 1998; Mansour \& al-Osimy, 1993). A satisfied patient develops a long lasting relationship with the health care provider. For health care organizations, a continuous fulfillment of patients` needs is significant to enhance the relationship with patients. This relationship is reflected in improved compliance, continuity of care, and generally better health outcomes (Fitzpatrick, 1991). Thus, patient satisfaction has been considered a critical factor in measuring the quality of health care organizations along with health outcomes (Margolis et al., 2003; Ley, 1990). Patient satisfaction has been frequently used as an indication of the overall quality of health care providers. It has been widely used by western countries as a significant indication of the quality of primary health care (PHC). Despite this, the concept and the methodology of assessing patient satisfaction are still underdeveloped in most developing countries (Harutyunyan et al., 2010). The introduction of PHC reform in most developing countries makes it essential to pay more attention to the concept and measurement of patient satisfaction. A structured and continuous evaluation of patients` perceptions of different dimensions in the provision of PHC service is needed (Pawlikowska et al., 2002).

Understanding patients` needs and expectations is crucial to PHC providers to improve patients' health (Palmer, 1991). As shown by Margolis et al. (2003) and Pölluste et al. (2000),Patient satisfaction may be enhanced by factors such as having sufficient information about patient's medical history, allowing sufficient time during consultation, making patients feel free to talk about their problems, and ensuring that the clinician did everything that should have been done in treating the patient. In contrast, poor communication with the patient, lack of interest in patient information, lack of consideration by medical staff have been reported as responsible for patient dissatisfaction (Holland et al., 1995; Bark et al., 1994;Weiss, 1988). Haddad et al. (1998) argue that in comparison to developed countries, patients in developing countries are highly sensitive to the perception of health care quality. This is true for a country as Egypt. This study aims to investigate patients' satisfaction with PHC services in Egypt. The study aims to study issues related to the provision of health care services at the primary level in two Egyptian governorates: Alexandria and Sohag. Alexandria is regarded as an urban governorate, while Sohag governorate is rural. The comparison is useful in exploring differences including strengths and weaknesses. This is also useful in introducing possible solutions for problems as well as methods of improving the quality of PHC services. 


\section{Determinants of Patient`s Satisfaction in PHC}

Health care quality is usually described using effectiveness, efficiency, optimality, legitimacy, equity, and acceptability (Donabedian, 1992). Acceptability is related to the ability of health care provider to meet patients` wishes, desires, and expectations (Pölluste et al., 2000). Acceptability reflects many features that are closely related to the concept of quality including accessibility, patient-doctor relation, amenities, and cost of care. Donabedian (1992) alongwith Øvretveit (1990) argue that acceptability is an adequate criterion that reflects quality of health care from patient's point of view. Further, acceptability is an indication of how patients evaluate health care providers. Researchers concerned with measuring patient satisfaction to evaluate quality of health care have argued that measuring health care quality should not be limited to clinical effectiveness or economic efficiency; rather it should include social acceptability as an important quality objective (Doll, 1993; Donabedian, 1992; Maxwell, 1984; Donabedian, 1980). However, (Donabedian, 1988 \& 1980) argues that patient satisfaction itself is an important outcome of health care organizations. Research review in the area of measuring satisfaction shows that satisfaction is multi-factorial, i.e. it is possible to identify different determinants of satisfaction. This is also true for measuring patient satisfaction. Researchers concerned with studying patient satisfaction have used a wide range of measurement tools depending on their definition of `satisfaction` (Al-Qatari \& Haran, 1999). Thompson \& Sunol (1995) argue that an accurate and satisfactory evaluation of quality improvements efforts should not be based on staff assessment only rather it should include patients 'views. Thompson \& Sunol explain that patients' perception of quality influence their selection of health care alternatives. Thus, no sole factor can be considered as the only contributor to satisfaction and/or dissatisfaction.

Calnan et al. (1994) argue that in assessing patients` satisfaction, the main emphasis should be placed on doctor-patient relationship and professional skills rather than accessibility and availability of health services. Some researchers have argued that there is no or a little relationship between patient satisfaction and their socio-demographic characteristics (e.g. Weiss, 1988). Others have related patient characteristics to their level of satisfaction with health care services. Despite contradictory research findings, age and gender have been identified as the most influential demographic factors to patient satisfaction (e.g. Biderman et al., 1994, Ware et al., 1978). In general, older patients are argued to be more satisfied with health care service than younger patients. However, it is unclear whether this is related to difference between generations or whether individuals are easily satisfied when they get older. Except for few exceptions (e.g. Biderman et al., 1994), research shows that females tend to be more satisfied than males. Whilst most research reports a positive relationship between level of education and patient satisfaction, few argue that less educated patients are more satisfied than their higher educated counterparts (e.g. Ware et al., 1978). Nevertheless, patients' satisfaction with the general practitioner (GP) is an important factor that influences patients' satisfaction with PHC. Some studies show that patients at the PHC level prefer to deal with specialists (e.g. Thompson\& Sunol, 1995); others have reported a high level of patients` satisfaction with GPs (Pickin et al., 2004). Thus, regardless of the impact of demographic factors, satisfaction with GPs is a major factor that influences patients`satisfaction.

Primary Health Care (PHC) in Egypt: The Egyptian health sector could be described as vertical, centralized, and fragmented (EHSRP, 2003). This limits Egypt's opportunities to take advantage of available practices in medicine and realizing potential gains for improvements in efficiency and equality. Access to health care around the country is inequitable due to uneven geographic distribution of services as well as differences in levels of economic status. Rural people pay high prices to obtain health services from the private sector as free public health care services are limited in terms of accessibility, availability, and quality (EHSRP, 2003). In 1996, the Egyptian government through the Ministry of Health and Population (MOHP) introduced a health reform program to overcome problems of health care system including health outcomes, accessibility, efficiency, quality, clinical effectiveness and consumer satisfaction. Actual implementation of reform has not started until 2003. The first stage of the reform program was concerned with the primary health care level (PHC). The reform program aimed to develop an efficient and high quality primary care service that is financially affordable, provides a significant level of benefits to the population and distributes these benefits and associated costs fairly according to people`s needs and ability to pay (MOHP, 2004a; 2004b). The decision to start reform implementation at the PHC level was influenced by the fact that most Egyptians, including 
those with low income, used to seek PHC services in the private sector as public PHC services were perceived as low quality (MOHP, 2004a).

Research Objectives: This study aims to explore patients' satisfaction with health care services provided at primary care level in Egypt. This aim cannot be achieved without investigating differences in patients' satisfaction in urban and rural Egyptian governorates. Thus, the study aims to achieve the following objectives:

- To identify the major dimensions of patients`satisfaction with primary health care in Egypt.

- To illustrate differences across urban and rural governorates with respect to patients' satisfaction.

- To justify differences in patients' satisfaction.

- To investigate the gap in the provision of primary health care services between rural and urban governorates.

- To propose solutions for problems and/or methods of improvement to fill in the gap between rural and urban areas.

\section{Methodology}

Setting and Participants: The study started in August, 2011 and extended to December, 2012. PHC services are provided through family health units. Ten PHC units were included in each governorate. Participants in each PHC unit presented patients visited the clinic on the time of conducting the study. A period of one week to 10 days was spent in each facility. A total of 693 patients participated in the study including 326 participants in Alexandria (173 males, 153 females) and 367 in Sohag (169 males, 198 females). The first stage of data collection was conducted in Alexandria. This was followed by collecting data from Sohag governorate. The researcher aimed to increase the number of participants in Sohag to gain a better understanding of issues that were not raised in Alexandria. The study was conducted in the waiting area of the PHC unit. Participants were randomly selected from registered patients who came to the clinic to see the doctor. Registration implies that the patient is geographically served by the PHC unit (lives in the geographical zone of the clinic). Data collection extended over a long time period. Thus, percentage of registered patients differed across PHC units. However, the average registration rate in Alexandria was higher than Sohag. On average, $68 \%$ of participants in Alexandria were registered compared to $32 \%$ in Sohag. Three different methods of registration were used: (i) personal registration, where the patient fills in the registration form personally at the GP clinic; (ii) registration on the patient list at the reception before seeing the doctor; and (iii) registration by another person or by the nurse at the reception. Whilst Registration in Alexandria relied heavily on personal registration at the GP clinic, the highest percentage of registration in Sohag was done by another person or the nurse - Table 2 .

Table 2: registered patients according to registration method

\begin{tabular}{lll}
\hline Method of registration & $\begin{array}{l}\text { Alexandria } \\
(\mathbf{n = 3 2 6}) \\
\text { \%o of registered patients }\end{array}$ & $\begin{array}{l}\text { Sohag } \\
(\mathbf{n = 3 6 7 )}\end{array}$ \\
\hline Personal registration at the GP office. & 48 & 20 \\
Personal registration at the reception. & 36 & 32 \\
Registration by another person or the nurse. & 16 & 48 \\
\hline
\end{tabular}

Design: Structured Questionnaires were used for data collection. Questionnaires were administered by the researcher and two research assistants with previous experience in conducting research and data collection. Questionnaire design was guided by points used by other researcher to assess patient satisfaction (Al-Sakkak et al., 2008; Margolis et al., 2003; Pawlikowska et al., 2002; Al-Doghaither \& Saeed, 2000; Al-Qatari \& Haran, 1999; Thompson \& Sunol, 1995; Biderman et al., 1994). The researcher aimed to make the research design simple to facilitate data collection from patients especially in Sohag governorate. Patients were asked to decide whether they agree (yes) or disagree (no) with each statement in the questionnaire. This was thought to be the simplest and most accurate method of data collection in rural governorates with high illiteracy. Five items were measured in the questionnaire: overall satisfaction, accessibility, patient-doctor relationship, clinic amenities, and satisfaction with GP/doctor. Although cost is one of the factors that are commonly used 
for assessing patients`satisfaction, it was not included in this study as services in PHC units are free. Each factor was measured using a number of other factors as follow:

a. Overall satisfaction:

- improvement in the PHC unit

- no improvement in the PHC unit

- Deterioration in the PHC unit.

\section{b. Accessibility}

- Location of the clinic.

- $\quad$ availability of doctors

- explaining the new system

\section{c. Patient-doctor relationship}

- effectiveness of medicine prescribed

- doctor`s willingness to listen to patients

- clarity of explanation of patient problem

- explanation of treatment by the doctor

- doctor`s willingness to answer patients` questions.

\section{d. Clinic amenities}

- availability of modern equipment

- cleanliness of clinic.

- preparation of waiting area (e.g. chairs).

- waiting time.

- availability of female reception area.

- availability of sufficient examination rooms.

- communication with nurses.

\section{e. Satisfaction with GPs}

- preference of GPs

- Preference of specialists.

- $\quad$ No preference.

Reliability of the questionnaire was tested with Cronbach`s alpha $(0.80)$.

Analysis: Analysis of co-variance was used to calculate the significance of satisfaction with accessibility, patient-doctor relationship, amenities, and GPs in the two governorates. Demographic factors were also included. Data was processed using SPSS program. Multiple comparisons were carried out by one-way analysis of variance (ANOVA) with post tests, where appropriate. Significance of the relationship between respondents' characteristics and patients' satisfaction with PHC services was studied using Multiple Regression and ANOVA with confidence interval limits (95\%) and $p$-values $(\alpha=0.05)$.

\section{Results}

a. Overall satisfaction with the changes introduced to the PHC unit: In general, patients in Alexandria are more satisfied with PHC services than patients in Sohag. 68\% of patients in Alexandria believe that the situation in PHC units has improved compared to $46 \%$ in Sohag. No significant correlation was found between level of satisfaction and gender, marital status, or age. Table 3 shows differences in patients assessment to changes in PHC units in Alexandria and Sohag governorates.

The difference in level of satisfaction between registered and non-registered patients was statistically significant $(\mathrm{p}<0.0001)$. Also, a significant difference in level of satisfaction was found between respondents in Alexandria and their counterparts in Sohag $(\mathrm{p}<0.0001)$. No relationship was found between level of satisfaction and gender, marital status, or age $(\mathrm{p}=0.001)$. 
Table 3: Patients` satisfaction with the overall system in PHC units

\begin{tabular}{llr}
\hline Patients` opinions about changes in PHC unit & $\begin{array}{l}\text { Alexandria } \\
\text { \% of patients }\end{array}$ & $\begin{array}{r}\text { Sohag } \\
\text { who agree }\end{array}$ \\
\hline The situation in the PHC unit has improved. & 68 & 46 \\
No change. & 18 & 16 \\
The situation in the PHC unit has become worse & 14 & 38 \\
\hline
\end{tabular}

b. Accessibility: In this study, measuring accessibility focused on three main factors: location of the PHC facility, availability of doctors, and awareness of the changes taking place at the PHC facility. Differences in patients'satisfaction in Alexandria and Shag are summarized in Table 4. Although respondents' satisfaction with the location of PHC units in both governorates is very close (73\% in Alexandria versus $78 \%$ in Sohag), satisfaction with the availability of doctors in Sohag is higher than Alexandria (82\% in Sohag compared to $42 \%$ in Alexandria).

Regarding awareness of the changes taking place at the PHC level, 28\% of patients in Sohag agreed that they were informed about the new system. This percentage increased to $68 \%$ in Alexandria.

Table 4: Patients`satisfaction with accessibility

\begin{tabular}{llc}
\hline Satisfaction with accessibility & Alexandria & $\begin{array}{c}\text { Sohag } \\
\text { \% of patients who agree }\end{array}$ \\
\hline Location of the clinic is close to my house. & 73 & 78 \\
Doctors are available in the clinic most of the day & 42 & 82 \\
The new system in the clinic was clearly explained to us. & 68 & 28 \\
\hline
\end{tabular}

c. Patient-doctor relationship: Five factors were used to measure satisfaction with patient-doctor relationship. These factors include: effectiveness of medicine prescribed, listening to the patient, clarity of explanation of patient's problem, explanation of treatment and side effects, and answering patients ' questions. Differences in patient-doctor relationships across the two governorates are summarized in Table 5. Statistics show that patients in Alexandria tend to be more satisfied with their doctors than their counterparts in Sohag. A low significant difference was found in the level of satisfaction with doctors between Alexandria and Sohag $(\mathrm{p}<0.01)$.

Table 5: Patients` Opinions of Patient-doctor relationship

\begin{tabular}{llc}
\hline Indications of patient-doctor relationship & Alexandria & Sohag \\
& & \% of respondents who agree with yes \\
\hline 1. Doctors are qualified enough to prescribe the right medicine. & 78 & 43 \\
2.Doctors spend enough time listening to my complaint & 69 & 26 \\
3. The doctor easily and clearly explains my problem. & 46 & 33 \\
4. The doctor spends enough time explaining the type of & 45 & 28 \\
treatment and how to use. & & 18 \\
5. Doctors welcome any questions and answer them clearly. & 60 & \\
\hline
\end{tabular}

d. Patients`satisfaction with amenities: Amenities in each governorate was assessed using eight factors: availability of modern equipment, cleanliness of the clinic and examination rooms, preparation of waiting areas (e.g. chairs),waiting time, cooperation of nurses, and availability of sufficient examination rooms. A significant difference was found in patients` satisfaction with amenities across Alexandria and Sohag. As shown in Table 6, respondents' satisfaction with amenities differs across the two governorates. This is proven by comparing the percentage of satisfied respondents with the first six factors. In contrast, patients in the two governorates are not highly satisfied with nurses (32\% in Alexandria compared to $22 \%$ in Sohag). 
Table 6: Patients`satisfaction with amenities

\begin{tabular}{llc}
\hline Satisfaction with amenities & Alexandria & Sohag \\
& & \% of respondents who agree with yes \\
\hline Availability of modern equipment & 78 & 43 \\
Cleanliness & 63 & 32 \\
Preparation of waiting area & 75 & 36 \\
Waiting time & 48 & 29 \\
Availability of female reception area & 34 & 73 \\
Cooperation of nurses & 32 & 22 \\
Availability of sufficient examination rooms & 56 & 32 \\
\hline
\end{tabular}

e. Satisfaction with the GP/doctor: This factor is mainly concerned with measuring respondents' satisfaction with being examined by a GP and then referred to a specialist, if needed. Measuring satisfaction with GPs is considerably important because the concept of the family health doctor was first introduced by the reform program. Before reform, patients were examined by specialists in PHC units. Specifically, general practice was not introduced in medical schools until 2004. Whilst 48\% of respondents in Sohag are satisfied by GPs, only 32\% are satisfied in Alexandria - Table 7. 53\% of respondents in Alexandria are satisfied by specialists compared to $24 \%$ only in Sohag. For $28 \%$ of respondents in Sohag, it does not make a difference to be examined by a specialist or a GP. This is compared to $15 \%$ in Alexandria. No significant difference was found between level of satisfaction and gender, age, or marital status in both governorates $(\mathrm{P}=0.001)$

Table 7: Patients`satisfaction with GPs

\begin{tabular}{llc} 
Satisfaction with doctors & Alexandria & Sohag \\
& & \% of respondents who agree with yes \\
\hline I am satisfied with being examined by a GP. & 32 & 48 \\
It doesn't make a difference to be examined by a GP or a & 15 & 28 \\
$\begin{array}{l}\text { specialist. } \\
\text { I want to be examined only by a specialist. }\end{array}$ & 53 & 24 \\
\hline
\end{tabular}

A positive correlation was found between informing patients with the changes taking place at the PHC unit and their level of satisfaction with GPs. Respondents who were well informed about these changes were satisfied with being examined by a GP and then referred to a specialist $(r=0.29, p<0.01)$. Also, a positive correlation was found between satisfaction with the GP and overall satisfaction with the changes introduced at the PHC level $(r=0.26, p<0.01)$.

\section{Discussion}

This study aims to study patients' satisfaction with the changes introduced to PHC level in Egypt. As a part of the Egyptian health sector reform program (EHSRP) a set of clinical and nonclinical changes are introduced to PHC units. Although the reform program was introduced in 1997, actual implementation of reform has not started until 2004. The introduction of the concept of family doctor to the PHC level is one of the most significant changes that have been introduced by the reform program. For many years Egyptians have been examined by specialists at different levels of health care services. Changing this concept and pursuing patients to accept being examined by a GP and referred to a specialist, if needed, is a crucial issue that highly influences patients' satisfaction with their doctors and the overall services provided at the PHC units. Two factors highly influence patients' satisfaction with accessibility of PHC services. The first factor is the availability of doctors in the health care unit. The difference in respondents' satisfaction with the availability of doctors in Alexandria and Sohag can be explained by a geographic and cultural context. The geographic location of Alexandria as a Mediterranean governorate is different from the location of Sohag in Upper Egypt. Alexandria is located at the North West end of the River Nile Delta in a sandy strip of the Mediterranean south coast (Abbady, 1992). Alexandria port is one of the biggest ports in the Mediterranean and its lighthouse has 
been named one of the `seven miracles of the world (Bayoumy, 2004). There are many tourist attractions located inside the city and Alexandria historical international library is one of the most important tourist attractions in Alexandria (Abbady, 2002). Alexandria enjoys high education and economic levels. On the other hand, Sohag is located in the middle of Upper Egypt (Ministrial Council, 2005). The governorate dates back to ancient Egyptian history. By today`s standards, Sohag population is classified as highly conservative and closed.

The geographic location of the two governorates influences doctors' willingness to stay in the PHC unit for a long time. Doctors working in PHC units in Sohag are nonresidents. They find it difficult to be a part of the community because of the conservative and closed culture. Also, opportunities for socialization and entertainment are limited. Because of that, doctors remain in the health care unit most of the day. Also, doctor`s accommodation is usually inside the health care unit. This makes it easy for any patient to find a doctor along the day. In contrast, doctors in Alexandria whether residents or non residents, have a wide space for socializing and entertaining. They usually spend few hours in the health care unit (usually from 10am2pm). Unlike Sohag, most of doctors in Alexandria are dedicated to their private clinics that are considered as their major source of income. The second factor that influences accessibility is the extent to which patients are being informed about changes taking place at the PHC level. This is closely related to the process of "reform promotion". The two governorates differ in reform promotion which influences patients` satisfaction with accessibility of health care services. Alexandria governorate is more concerned with promoting the reform program than Sohag. Promoting reform in Alexandria uses different ways of promotion such as meeting on a weekly basis with patients inside the PHC unit, arranging conferences and exhibitions in schools, universities, and social clubs, and visiting families in their houses to explain the new system. This is not the case in Sohag as promoting reform does not exceed informal discussion between patients and doctors within the clinic during examination time.

Review of the literature demonstrates that GPs have been the basis of providing primary health care services in many developed (e.g. UK, New Zealand, USA) as well as developing health care systems (e.g. South Africa, Zambia, Ghana) (Gilson et al., 2003; Flood, 2000; Agyepong, 1999; Barnett, 1993; Culyer \& Meads, 1992). Despite this, interviews held for the purpose of this study show that Egyptians have a negative perception of GPs. For many Egyptians, GPs are unqualified and unreliable. This may be justified by the nature of medical education in Egypt that overlooked general practice and focused on specialties. This negative attitude towards GPs is deeply rooted in the Egyptian community which makes it difficult to change people`s attitude to GPs. Despite the negative perception of GPs, $32 \%$ of respondents in Alexandria compared to $48 \%$ in Sohag are satisfied with being examined by a GP. This is highly influenced by the cultural context in the two governorates. The conservative culture as well as the strong norms and traditions in Sohag highly influences patients` acceptance of GPs. In Sohag and other Upper Egypt governorates, doctors are highly respected, regardless of their specialty. Meanwhile, the low education level makes it unclear to most patients as what is the difference between a GP and a specialist. Whether a specialist or a GP any doctor in Sohag is highly valued and respected. On the other hand, the cultural context in Alexandria has also influenced acceptance of GPs. Alexandria enjoys high education and economic levels. People in Alexandria are well educated and open minded which makes it easier to accept new ideas. Thus, reform promotion efforts in Alexandria facilitates people`s acceptance of GPs. However, this needs effort and time to introduce and discuss the new system with patients. Thus, the cultural context in Sohag facilitates acceptance of GPs more easily and rapidly than Alexandria.

Although the reform program is concerned with improving the infrastructure of PHC units as well as providing PHC units with needed equipment, machines and medical preparations, a significant difference is found in respondents' satisfaction with amenities in both governorates. Statistics shown in Table 6 implies that amenities in Alexandria PHC units are better than PHC units in Sohag. This draws attention to the level of concern given to rural governorates. Waiting time is an issue that was raised in interviews. Two factors are responsible for the length of waiting time: patient's registration and ease of access to family folders. Although waiting time in Alexandria is shorter than Sohag, it is problematic. Registration system in both governorates represents a serious problem. The process of registration begins when the patient comes to the clinic asking for a medical consultation. In future visits, waiting time for registered patients gets shorter. Ease of accessing patients` family folders is another problem. This problem is caused by the lack of computerized registration 
systems. Whilst computers are used in most of the units in Alexandria, manual registration is still used in all units in Sohag. Thus, time and effort are wasted in registering the patient and accessing their folder rather than getting the patient examined by a doctor. Nurses` performance at PHC units highly influences patients` satisfaction. Patients in both governorates are dissatisfied with the attitude of nurses, and their communication and cooperation with patients. Patients argue that nurses can hardly help patients, listen to their complaints, or answer their questions. Meanwhile, nurses don't participate seriously in explaining the new system to patients. Further, respondents argue that nurses have no role in the clinic either with patients or with doctors.

Improving Patient's Satisfaction With PHC Services in Egypt: A Need for Serious Actions: The study shows a gap in patient's satisfaction across Alexandria and Sohag governorates. This implies a difference in reform implementation across urban and rural governorates. Some actions are needed to improve PHC level and raises patient's satisfaction. These actions are significant for rural areas:

1- A computerized registration system: Registration plays an important role in determining patients' satisfaction. It is arguable that registered patients are better informed with the new system, more satisfied with their doctors, and do not suffer from the long waiting time. Manual registration system is still used in Sohag which negatively influences patients' satisfaction. It is important to introduce computerized registration systems to PHC facilities in Sohag. This is likely to speed up and facilitate patients' registration. A computerized system makes it easier for doctors, nurses, and administrative to access family folders for different purposes. Introducing computerized systems is accompanied by the need to train personnel responsible for registration. This training is needed to ensure the most efficient utilization of the system.

2- More concern with reform promotion: Introducing and explaining the reform program to people is likely to prepare them to accept the new system. It conveys a message that the new system cares about people and this is influential in gaining people`s support and reducing their resistance level. Reform promotion needs more attention in Sohag governorate. As a rural governorate with low education level, reform promotion must be given more attention than other urban governorate such as Alexandria. In promoting the reform program, it is recommended to use TV and radio programs in local and national channels. Also, home visits by marketing groups to families in rural areas are highly influential. Home visits should focus on explaining the benefits of the new system to gain people`s acceptance. Advertisement in newspapers and magazines might be used however; they are not expected to have the same impact of TV programs and home visits.

Training of nurses: Nurses`attitudes and behaviors negatively influence patients` satisfaction in Alexandria and Sohag. Nurses do not have a real role in PHC units. The way they communicate with patients conveys a message that 'questions are unwelcomed'. Also, nurses do not have a real role in supporting doctors. Thus, there is a need to train nurses on two main aspects. First, nurses must be trained on communication and behavioral skills. This training has to focus on raising nurses` awareness of their role in helping patients. Second, clinical training is needed to improve nurses' abilities to support doctors during examination as well as in other clinical issues.

3- More concern with amenities: Equal allocation of budget across rural and urban governorates is a necessity. This ensures consistency of reform implementation. Preparation of PHC units has differed widely across Alexandria and Sohag. Whilst Alexandria is given a high attention in improving infrastructure and amenities, Sohag suffers from poor facilities and preparations of PHC units. PHC units in Sohag must be provided with needed machines and equipment. Also, waiting areas and examination rooms have to be well prepared. A special waiting area for females should be well prepared and there is a need for more examination room.

Research Limitations: Although this study explores important differences in the provision of primary health care services in rural and urban Egyptian governorates, results cannot be easily generalized to all Egyptian governorates. Further research in other urban and rural governorates is needed to investigate applicability of the findings of this study. Further research could be useful in exploring further differences in 
PHC level across urban and rural areas. This body of research is considered as the cornerstone of improving PHC and raising patients' satisfaction in Egypt.

\section{References}

Abbady, M. (1992). Egypt Since Great Alexander Time to the Arab Opening Time (Cairo: Anglo Bookshop).

Abbady, M. (2002). Alexandria Ancient Library: History and Destiny $2^{\text {nd }}$ edn., (Cairo: Supreme Council of Momentums).

Agyepong, I. (1999). Reforming Health Service Delivery at District Level in Ghana: the Perspective of a District Medical Officer. Health Policy and Planning, 14(1), 59-69.

Al-Doghaither, A. H. \& Saeed, A. A. (2000). Consumers`satisfaction with primary health services in the city of Jeddah, Saudi Arabia. Saudi Medical Journal, 21(5), 447-454.

Al-Sakkak, M. A., Al-Nowaiser, N. A. \& Al-Abdrabulnabi, A. A. (2008). Patient satisfaction with primary care services in Riyadh. Saudi Med J., 29(3), 432-436.

Al Qatari, G. \& Haran, D. (1999). Determinants of users' satisfaction with primary health care settings and services in Saudi Arabia. International Journal for Quality in Health Care, 11(6), 523-531.

Baker, D. W., Hayes, R. \& Fortier, J. P. (1998). Interpreter use and satisfaction with interpersonal aspects of care for Spanish-speaking patients. Med Care, 36, 1461-1470.

Bark, P., Vincent, C. H. \& Jones, A. (1994). Clinical complaints: a means of improving quality of care. Qual Health Care, 3, 123-132.

Barnett, J. R. (1993). Does the Geographic Distribution of Physicians Reflect Market Failure? an Examination of the New Zealand Experience 1981-1987. Environment and Planning, 25, 3-22.

Bayoumy, A. (2004). Alexandria Governorate, (Cairo: Center for Political and Strategic Studies, Al Ahram Library).

Biderman, A., Carmel, S. \& Yeheskel, A. (1994). Measuring patient satisfaction in primary care: a joint project for community representatives, clinic staff members and a social scientist. Fam Pract, 11, 287-291.

Calnan, M., Katsuuyiannopoulos, V. \& Ovcharov, V. K. (1994). Major determinants of consumer with primary care in different health systems. Fam Pract, 11, 468-478.

Culyer, A. J. \& Meads, A. (1992). The United Kingdom: effective, efficient, equitable? J Health Polit Plicy Law, $17(4), 667-88$.

Doll, R. (1993). Monitoring the national health service. proc $r$ soc med, 66, 729-740.

Donabedian, A. (1980). The definition of quality and approaches to its assessment. Volume 1: exploration in quality assessment and monitoring', (ann arbor, MI: health administration press).

Donabedian, A. (1988). The quality of care: how can it be assessed? J Am Med Assoc, 260, 1743-1748.

Donabedian, A. (1992). Defining and measuring the quality of health care`. In Wenzel, R.P. ed. ‘assessing quality health care. Perspectives for clinicians', (Baltimore: Williams \& Wilkins).

EHSRP. (2003). Analysis and Reform Program', MOHP, Cairo, Egypt.

Fitzpatrick, R. (1991). Surveys of patient satisfaction. I. designing a questionnaire and conducting a survey. $\mathrm{Br}$ Med J., 302, 1129-1132.

Flood, C.M. (2000). International Health Care Reform: A Legal, Economic, and Political Analysis, (London: Routledge).

Gilson, L., Doherty, J. \& Lake, S. (2003). The SAZA study: implementing health financing reform in South Africa and Zambia. Health Policy and Planning, 18, 31-46.

Haddad, S., Fournier, P. \& Potvin, L. (1998). Measuring lay people`s perceptions of the quality of primary health care services in developing countries. Validation of a 20-item scale', int $j$ qual health care, 10, 93-104.

Holland, M. S., Counte, M. A. \& Hinrichs, B. G. (1995). Determinants of patient satisfaction with outpatient surgery. Qual Manag Health Care, 4, 82-90.

Harutyunyan, T., Demirchyant, A. \& Thompson, M. (2010). Patient satisfaction with primary care in Armenia: good rating of bad services? Health Serv Manage Res, 23(1), 12-17.

Ley, P. (1990). Communication with patients: improving communication, satisfaction, and compliance', (London: Chapman and Hall).

Mansour, A. A. \& Al-Osimy, M. H. (1993). A study of satisfaction among primary health care patients in Saudi Arabia. J Commun Health, 18, 163-173. 
Margolis, S. A., Al-Marzouq, S. \& Revel, T. (2003). Patient Satisfaction with Primary Health Care Services in the United Arab Emirates. International Journal for Quality in Health Care, 15(3), 241-249.

Maxwell, R. J. (1984). Quality assessment in health. Br Med J., 288, 1470-1472.

Ministrial Council. (2005). Information and Decision Support Centre, Description of Alexandria Governorate, Cairo, Egypt.

MOHP. (2004a). Family Health Facility Implementation Manual', CDTSP, HSRP, Cairo, Egypt.

MOHP. (2004b). DPO guidelines', HSRP, Cairo, Egypt.

Øvretveit, J. (1990). Quality health services', research report, BIOSS, (Oxbridge, UK: Brunel university).

Palmer, R. H. (1991). Quality management in ambulatory care`. In Couch, J.B. (ed.) 'health care quality management for the $21^{\text {st }}$ century', (Tampa, FL: Hillsboro Printing Co.)

Pawlikowska, T. R. B., Nowak, P. R. \& Szumilo-Grzesik, W. (2002). Primary care reform: a pilot study to test the evaluative potential of the patient enablement instrument in Poland. family practice, 19(2), 197 201.

Pickin, D. M., O'Cathain, A. \& Morgan, A. B. (2004). The impact of general practice co-operative on accident and emergency services, patient satisfaction and GP satisfaction. family practice, 21(2), 180-182.

Pölluste, K., Kalda, R. \& Lember, M. (2000). Primary health care system in transition: the patient`s experience. international journal for quality in health care, 12(6), 503-509.

Thompson, A. G. H. \& Sunol, R. (1995). Expectations as determinants of patient satisfaction: concept, theory and evidence. int $j$ qual health care, 7, 127-141.

Ware, J. E., Davies-Avery, A. \& Stewart, A. L. (1978). The measurement and meaning of patient satisfaction. Health Med Care Serv Rev, 1, 3-15.

Weiss, G. L. (1988). Patient satisfaction with primary medical care. Med care, 26, 383. 